\title{
Rates of prenatal screening across health care regions in Ontario, Canada: a retrospective cohort study
}

\author{
Robin Z. Hayeems PhD, Michael Campitelli MSc, Xiaomu Ma MSc, Tianhua Huang PhD, \\ Mark Walker MSc MD, Astrid Guttmann MDCM MSc
}

\section{Abstract}

Background: It is recommended that all pregnant women be offered screening for Down syndrome and open neural tube defects, but emerging prenatal tests that are not publicly insured may compromise access. We evaluated screening rates for publicly insured screening tests across health care regions in the province of Ontario and determined whether maternal, provider or regional characteristics are associated with screening uptake.

Methods: We conducted a population-based retrospective cohort study involving pregnant women in Ontario who were at or beyond 16 weeks' gestation in 2007-2009. We ascertained prenatal screening rates using linked health administrative and prenatal screening datasets. We examined maternal, provider and regional characteristics associated with screening uptake. Rate ratios (RRs) were estimated.

Results: Of the 264737 women included in the study, $62.2 \%$ received prenatal screening; uptake varied considerably by region (range $27.8 \%-80.3 \%$ ). A greater proportion of women initiated screening in the first rather than the second trimester $(50.0 \% \mathrm{v}$. $12.2 \%$ ). Factors associated with lower screening rates included living in a rural area versus an urban area (adjusted rate ratio 0.64 , $95 \%$ confidence interval $[\mathrm{Cl}]$ 0.63-0.66), receiving first-trimester care from a family physician or midwife versus an obstetrician (adjusted rate ratio $0.91,95 \% \mathrm{Cl} 0.90-0.92$, and $0.40,95 \% \mathrm{Cl} 0.38-0.43$, respectively) and being in a lower income quintile (adjusted $\mathrm{RR}$ for lowest v. highest $0.95,95 \% \mathrm{Cl} 0.94-0.96)$. Being an immigrant or a refugee was associated with higher screening rates.

Interpretation: There were significant maternal, provider and regional differences in the uptake of prenatal screening across the province. With discrepancies expected to increase with the emergence of noninvasive prenatal tests paid for out of pocket by many women, policy efforts to reduce barriers to prenatal screening and optimize its availability are warranted.

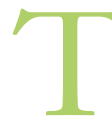
he Society of Obstetrics and Gynecology of Canada recommends that all pregnant women be offered a range of prenatal screening tests to identify pregnancies at risk of specific chromosome abnormalities and open neural tube defects. ${ }^{1}$ The tests were once offered only to women 35 years of age and older, but the recommendation has been extended to all age groups. ${ }^{1}$ Most women will gain reassurance that their fetus is unlikely to be affected. Those identified as having a high-risk pregnancy will be offered diagnostic testing to guide further counselling and decision-making about the course of the pregnancy and delivery of care. Professional guidelines do not specify the particular screening protocol to be used, because local infrastructure, timing of prenatal care and value-based preferences vary. They do specify, however, that a high-performing test be universally available to women, regardless of their ability to pay. ${ }^{1-4}$

Screening practices and performance parameters differ across jurisdictions ${ }^{5-8}$ and are shifting quickly. In the province of Ontario, 4 screening tests are used, but their availability and performance vary (Table 1). Increasingly, noninvasive prenatal testing for chromosome abnormalities (i.e., using maternal serum as a source of fetal DNA) is becoming commonplace, which reduces the demand for risk-bearing invasive prenatal diagnosis. ${ }^{9-11}$ Attention to access barriers is important, particularly in jurisdictions where noninvasive testing is not publicly funded. ${ }^{12-14}$ Despite international policies recom-

Competing interests: Robin Hayeems is an unpaid member of the Maternal-Child Screening Committee, which reports to the Provincial Council for Maternal and Child Health. No other competing interests were declared.

This article has been peer reviewed.

Correspondence to: astrid.guttmann@ices.on.ca

CMAJ Open 2015. DOI:10.9778/cmajo.20140110 
mending universal offer of prenatal screening, uptake varies by maternal preferences, ${ }^{15-20}$ provider practice patterns ${ }^{21-25}$ and maternal sociodemographic characteristics. ${ }^{26-32}$

In light of the shifting and increasingly market-driven landscape of prenatal screening in Canada, ${ }^{33}$ we examined the screening rates for publicly insured tests across health care regions in the province of Ontario. We also determined maternal, provider and regional factors associated with screening uptake.

\section{Methods}

\section{Study design}

We conducted a population-based retrospective cohort study involving pregnant women in Ontario (population 13 million) who were at or beyond 16 weeks' gestation and had an estimated conception date between Dec. 1, 2007, and Nov. 30, 2009. We chose the cut-off of 16 weeks' gestation because guidelines suggest that most women should be offered prenatal screening by this point. ${ }^{1}$ We used multiple linked health and demographic datasets from Ontario. The province provides universal health care insurance that includes access to all routine pregnancy care services for all legal residents.

\section{Data sources}

Regional prenatal screening laboratories routinely upload screening results into a centralized database, now called the Better Outcomes Registry and Network (BORN Ontario). Using encoded health card numbers, we linked the prenatal screening data to administrative health datasets housed at the Institute for Clinical Evaluative Sciences (ICES; linkage rate 94\%). The databases included the Discharge Abstract Database, the Same-Day Surgery Database and the National Ambulatory Care Reporting System administered by the Canadian Institute for Health Information. These databases contain demographic and clinical information from all Ontario-based acute care facilities, day surgery clinics and emergency departments, respectively. ${ }^{34}$ Other databases included the Ontario Health Insurance Plan (OHIP) fee-forservice claims file, which provides information on diagnostic and service provision for about $94 \%$ of physicians in the province; the Ontario Registered Persons Database, which includes demographic information for all residents eligible to receive health care in the province; the ICES physician database, which records physician demographics and specialties; and the Citizenship and Immigration Canada file for immigrants who have landed in Ontario since 1985. We used data elements known to have high validity (e.g., diagnostic codes from discharge abstracts, fee codes from the OHIP database).

\section{Study cohort}

We identified live births and stillbirths using hospital discharge data; gestational age at delivery was used to estimate conception date. ${ }^{35} \mathrm{We}$ excluded deliveries with an indeterminate gestational age. We identified spontaneous and therapeutic abortions using data from the Discharge Abstract Database, the Same-Day Surgery Database, the National Ambulatory
Care Reporting System and the OHIP database. Gestational age at abortion was used to estimate conception date and to exclude aborted pregnancies with a gestation of less than 16 weeks. We included aborted pregnancies without a recorded gestational age if the woman had an OHIP service code denoting care or diagnostic imaging at or beyond 16 weeks' gestation. We included 1 pregnancy per woman during the study period, giving priority to those that reached delivery and then those that occurred earliest within the study period.

\section{Outcome measure}

The primary outcome measure was uptake of prenatal screening. Five regional laboratories support prenatal screening in the province. We used the prenatal screening dataset to determine screening receipt and modality (Table 1 ). Women who received screening not conforming to routine modalities were classified as "Other."

\section{Other covariates}

We collected data on selected predictors shown to be associated with the uptake of prenatal screening. ${ }^{17,20,26,28-32}$ We categorized maternal age at delivery or abortion into 3 groups $(\leq 20 \mathrm{yr}$, $21-34$ yr or $\geq 35 \mathrm{yr}$ ). ${ }^{28}$ We linked all women to previous hospital admissions for delivery to determine maternal age at the time of first childbirth ( $\leq 20 \mathrm{yr}, 21-34 \mathrm{yr}$ or $\geq 35 \mathrm{yr}$ ). Age of 20 years or less at first delivery has been shown to be a strong indicator of social marginalization. ${ }^{36} \mathrm{We}$ enumerated parity by all previous deliveries $(0,1,2$ or $\geq 3)$ and identified those that were stillbirths. We assessed a history of possible or confirmed prior pregnancy complicated by a congenital anomaly in 2 ways: (a) we identified women who had had a spontaneous or therapeutic abortion in the 5 years before the conception represented in our cohort using records from the Discharge Abstract Database, the Same-Day Surgery Database, the National Ambulatory Care Reporting System and the OHIP database, ${ }^{37}$ and (b) we used a unique maternal-newborn matching number on the maternal and infant hospital birth records ${ }^{35,38}$ to identify prior delivery of a child with a congenital malformation diagnosed in hospital within 1 year after birth.

We used the postal code of residence at conception to link to 2006 census data to describe neighbourhood income quintiles (a proxy for socioeconomic status ${ }^{39,40}$ ) and the Local Health Integration Network (Ontario's 14 health regions). Each woman was assigned a Rurality Index of Ontario score specific to the year 2008, categorized as major urban (score 0-9), non-major urban (score 10-39) and rural (score $\geq 40$ ). ${ }^{41}$ The Local Health Integration Network was used descriptively and was not included in the multivariable model; rather, the rurality score was used as a measure of geographic location. We used the Citizenship and Immigration Canada dataset to determine immigration status (Canadian resident; immigrant [landed $\geq 5$ or $<5 \mathrm{yr}$ ago]; or refugee [landed $\geq 5$ or $<5$ yr ago]).

We used OHIP records for the 14 weeks following the estimated conception date to identify the first-trimester care provider for each woman in a hierarchical fashion. For women whose records showed billings for prenatal care visits, we chose the physician who provided most of those services 


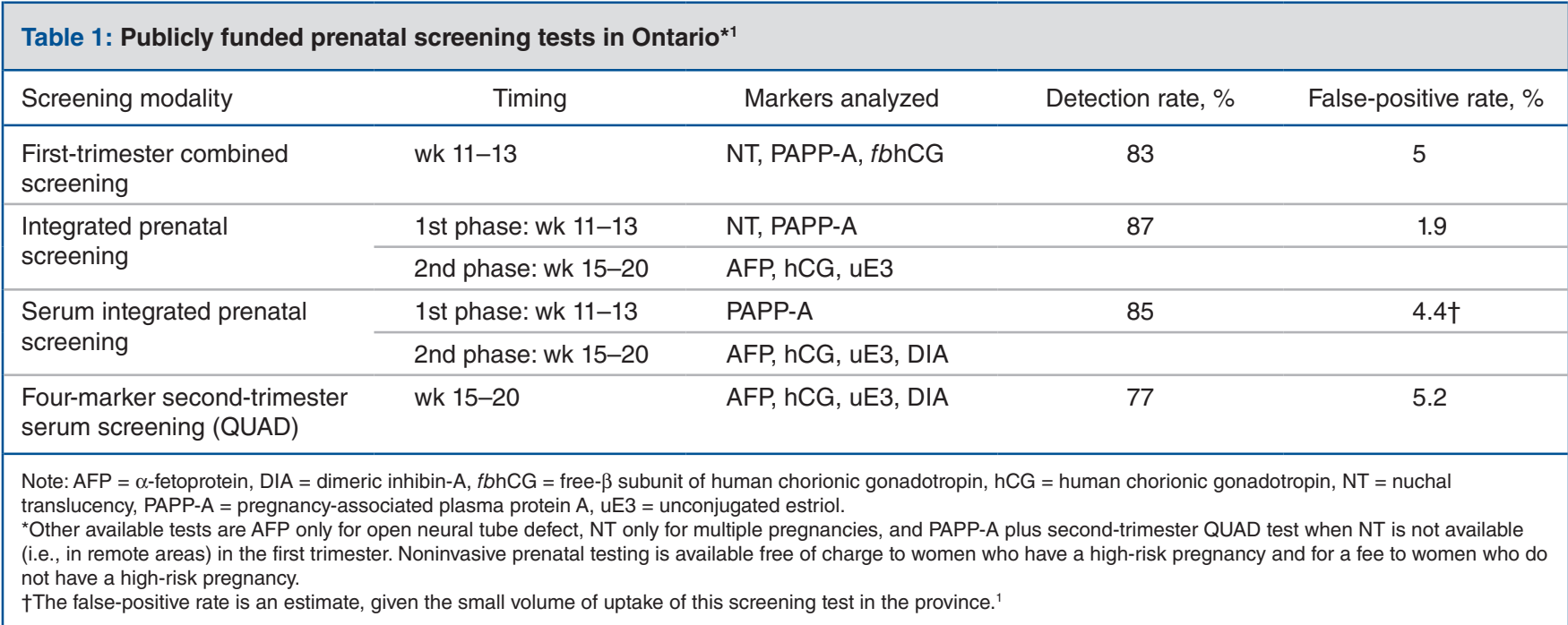

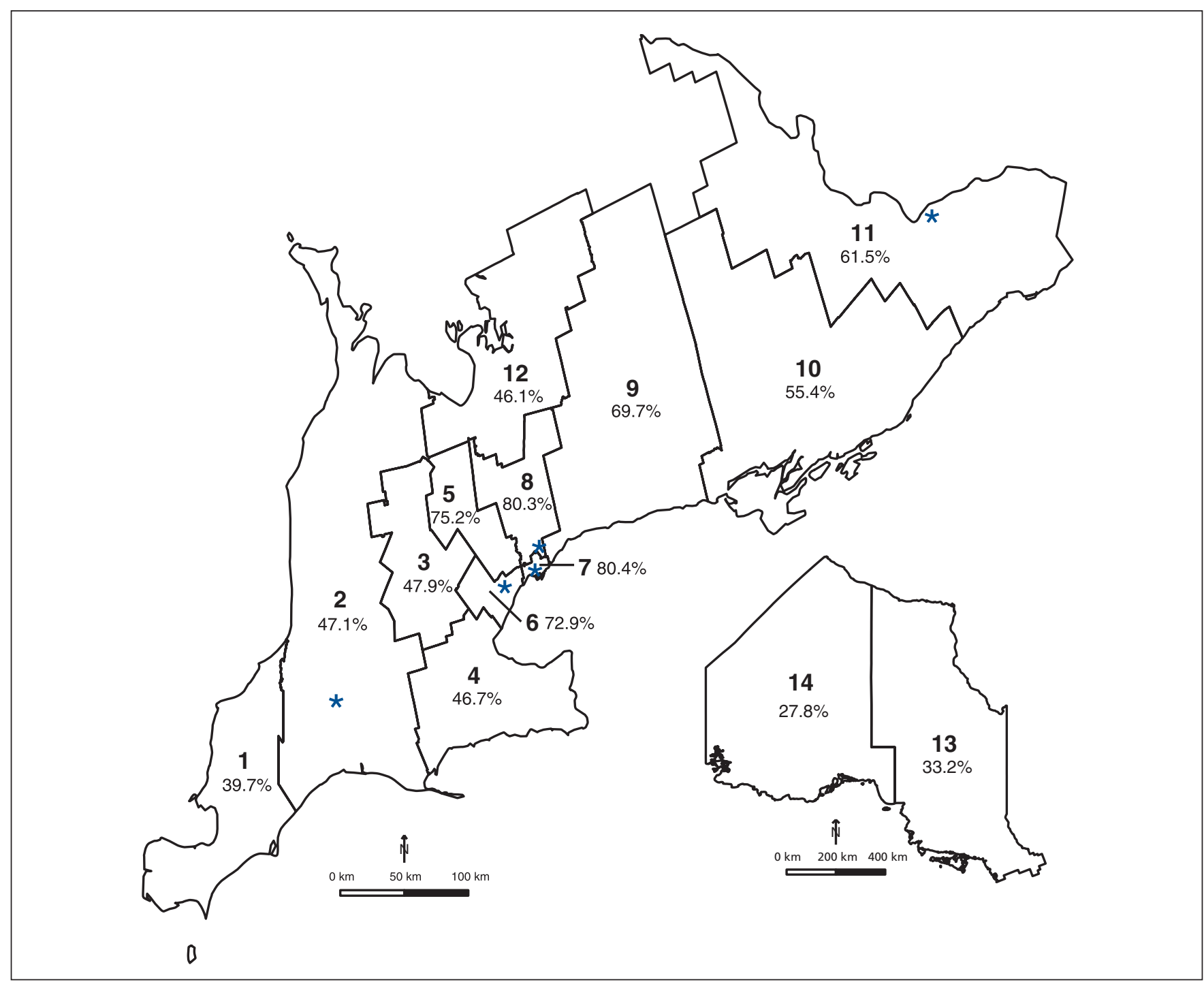

Figure 1: Map of prenatal screening rates across Ontario's 14 local health regions $(1=$ Erie St. Clair, $2=$ South West, $3=$ Waterloo Wellington, $4=$ Hamilton Niagara Haldimand Brant, $5=$ Central West, $6=$ Mississauga Oakville, $7=$ Toronto Central, $8=$ Central, $9=$ Central East, $10=$ South East, $11=$ Champlain, $12=$ North Simcoe Muskoka, $13=$ North East, $14=$ North West). ${ }^{*}=$ screening centre. 
(family physician or obstetrician); for the remaining women, we chose the family physician who provided most of the other primary care services during the first trimester. Women whose records showed outpatient billings to other physicians were assigned to the "other" group. For women with no billings, we identified the first-trimester care provider as a midwife (if there were midwifery-specific OHIP records during the pregnancy) or no care.

\section{Statistical analysis}

For women who had prenatal screening, we used the $\chi^{2}$ test to compare the timing of screening (first v. second trimester) among the selected predictors. Because the outcome (being screened) was common in our cohort, we used log-binomial regression analysis to examine the associations between factors of interest and receipt of screening. ${ }^{42}$ All predictors of screening identified a priori were entered into the multivariable model after we checked the variables for collinearity. We did not do additional analyses to test for confounding because we had no a priori hypotheses. Women with missing postal codes and other geographic identifiers could not be assigned a neighbourhood income quintile $(0.6 \%$ of cohort) or rurality index score ( $1.1 \%$ of cohort) and were included in a "missing data" category within those variables so that they could be included in the regression analyses.

We conducted statistical analyses using SAS 9.2 (SAS Institute Inc.). All tests were 2 -tailed; a $p$ value of less than 0.05 was used as the level of statistical significance.

\section{Ethics approval}

Ethics approval for the study was obtained from the Research Ethics Boards at the Sunnybrook Health Sciences Centre and the Children's Hospital of Eastern Ontario.

\section{Results}

We identified 264737 pregnant women (258 982 deliveries, 5755 abortions) at or beyond 16 weeks' gestation during the study period (Appendix 1, available at www.cmajopen.ca/ content/3/2/E236/suppl/DC1). Of these women, $62.2 \%$ received prenatal screening. Uptake varied considerably by health region, from less than $40 \%$ in the southwest and northern regions to $80.3 \%$ in central Toronto (Figure 1). Overall, $50.0 \%$ of the women initiated screening in the first trimester (either integrated prenatal screening or first-trimester combined screening), and $12.2 \%$ initiated screening in the second trimester (either serum integrated screening or the 4-marker QUAD test) (Figure 2). Initiation of screening was more common in the first trimester than in the second trimester across all health regions, reaching $57.6 \%-66.2 \%$ in the central, urban regions (regions 5-8); the difference in rates was marginal in 4 of the more remote regions (regions 1, 10, 13, 14) (Figures 1 and 2).

Among screened pregnancies, first- and second-trimester screening rates varied by maternal sociodemographic, regional and provider characteristics (Table 2). Specifically, first-trimester screening rates were higher among older women $(61.6 \%$ of women aged $\geq 35$ v. $25.4 \%$ of those aged $\leq 20 \mathrm{yr} ; p<0.001)$, women in higher income quintiles $(57.0 \%$ in highest v. $42.3 \%$ in lowest income quintile; $p<0.001)$ and women in major urban centres $(56.0 \%$ v. $24.9 \%$ in rural areas; $p<0.001)$. Rates of screening in the first trimester were lower among women who received prenatal care from a midwife $(26.8 \%)$ than among those receiving prenatal care from a family physician $(53.4 \%$ ) or an obstetrician $(66.0 \%)$ (Table 2 ). The median overall screening rate at the provider practice level was higher among obstetricians (median $75 \%$, inter-

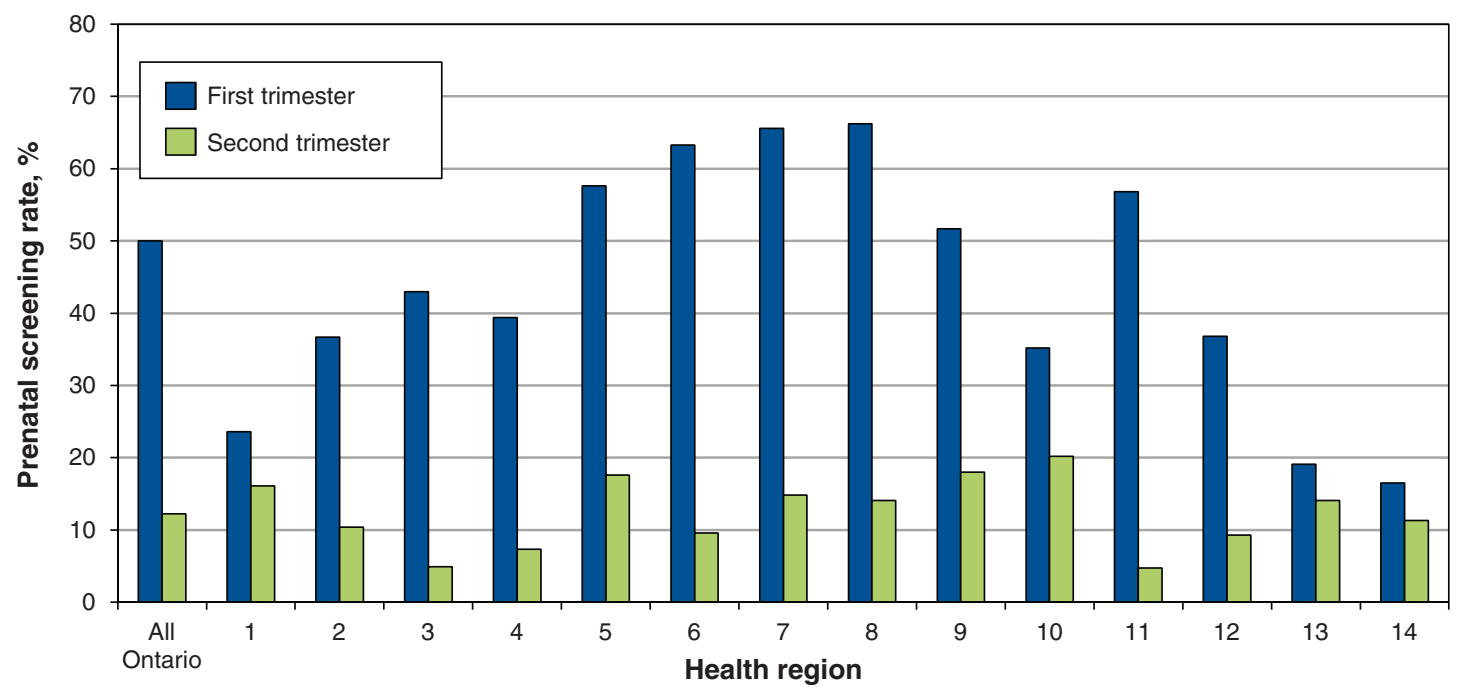

Figure 2: Screening rates by trimester across Ontario's 14 health regions $(1=$ Erie St. Clair, 2 = South West, $3=$ Waterloo Wellington, $4=$ Hamilton Niagara Haldimand Brant, $5=$ Central West, $6=$ Mississauga Oakville, $7=$ Toronto Central, $8=$ Central, $9=$ Central East, $10=$ South East, $11=$ Champlain, 12 = North Simcoe Muskoka, $13=$ North East, 14 = North West). 
quartile range [IQR] $52 \%-90 \%)$ than among family physicians (median 59\%, IQR 33\%-81\%).

After adjusting for all other predictors in the regression analysis, we found several factors associated with lower prenatal screening rates (Table 3). Living in a rural or nonmajor urban area versus a major urban area and receiving first-trimester care from a family physician or midwife versus an obstetrician were factors most strongly associated with lower screening rates; other factors were low maternal age at delivery or abortion, multiparity and being in a lower income quintile. Being an immigrant or a refugee, regardless of landing date, was associated with higher prenatal screening rates.

\section{Interpretation}

In this large, population-based study, we found significant differences in the use of prenatal screening in Ontario. Uptake of prenatal screening was higher in the first trimester than in the second trimester, and rates varied by health region and by urban and rural location. Receipt of screening was higher among women cared for by obstetricians and higher, although to a lesser extent, among women with fewer social risks. These differences existed in the context of high rates of prenatal visits in the first trimester and publicly funded prenatal screening tests.

The association between low screening rates and living in remote areas is consistent with findings from other populationbased studies ${ }^{28,31,32}$ and from survey reports of reduced rates of offered screening among rural providers. ${ }^{21-23,25}$ Reasons associated with low rates of offered screening included maternal age less than 35 years, lack of relevant family history and lack of patient request. ${ }^{21-23}$ Low volume of antenatal care (i.e., $<50$ pregnant women/yr) was also associated with low screening uptake. ${ }^{21}$ One study in Newfoundland and Labrador identified the same reasons for not offering screening and found that only $52.2 \%$ of family physicians surveyed routinely offered prenatal screening to all pregnant women. ${ }^{25}$ These studies also identified providers' generalized concerns about false-positive results, limited availability of abortion and supportive services for affected pregnancies, and the value-laden nature of screening for disabilities as barriers. ${ }^{21-23,25}$ Our finding that prenatal screening varied by type of prenatal care provider is important. Previous studies have not identified differences between provider groups in attitudes toward offering prenatal screening. Because $47 \%$ of pregnant women in Ontario receive at least some prenatal care from family physicians, ${ }^{34}$ further attention to practices of different providers is warranted.

The association of maternal sociodemographic characteristics, age and income-related barriers with lower screening rates reported in other jurisdictions had stronger effects than identified herein. ${ }^{28-30,32}$ Although predictors may differ across jurisdictions, age and income may have revealed stronger effects elsewhere because provider and regional effects were untested. Multiparity is often associated with older age and increased risk of aneuploidy; however, we found reduced screening uptake among multiparous women. Immigrant status was not identified as a barrier to screening, unlike findings in studies of other screening tests (e.g., Pap smears). ${ }^{43}$ Finally, initiation of screening was more common in the first trimester than in the second trimester across all health regions. As efforts shift toward strategies for noninvasive testing and first-trimester health assessments, ${ }^{44}$ higher rates of screening initiated in the first trimester suggest that Ontario is well positioned to move toward a first-trimester-based screening paradigm. ${ }^{33}$

\section{Limitations}

This study is limited in its ascertainment of screening uptake in that it does not reflect the offer of screening. The offer of screening is universally recommended, but the current infrastructure of databases precludes this analysis.

Other limitations include (a) potential overestimate of first-trimester screening rates, because some results coded as first-trimester screening may reflect intended but incomplete integrated prenatal screening; (b) our inability to capture uptake of noninvasive prenatal testing because of its recent entry into the screening environment in Ontario; (c) our exclusion of provider care not captured in OHIP billing data (e.g., salaried physicians at community health centres); (d) our incomplete capture of midwifery care and thus potential misclassification of first-trimester care provider.

A small proportion of women receive prenatal screening but no prenatal care, which reflects a likely underestimation of prenatal care provision.

We were constrained by the lack of data on other maternal characteristics shown to be associated with decisions to use prenatal screening, including personal and religious values, attitudes toward disability, and quality of information provided by health care providers..$^{15}$

Not all of our data definitions (e.g., gestational age at abortion) have been previously validated. The proportion of pregnancies that resulted in spontaneous or therapeutic abortion before 16 weeks' gestation was lower than population-based estimates; however, it suggests that we did not exclude eligible women from the cohort.

Finally, by linking only $94 \%$ of the screening records to ICES data, we may have slightly underestimated screening rates. However, there is no evidence to suggest that the linkage rate would vary by any of the characteristics evaluated.

\section{Conclusion}

Our study showed significant maternal, provider and regional differences in the uptake of prenatal screening across Ontario. Our findings have important implications for the delivery and evaluation of evolving prenatal screening services. With the emergence of noninvasive prenatal tests paid for out of pocket by women in some jurisdictions and the extension of services beyond the detection of aneuploidies and open neural tube defects to more common adverse pregnancy-related or developmental outcomes, ${ }^{42}$ ensuring access to prenatal screening in an increasingly strained fiscal environment will be challenging. Education of and preference-sensitive decision-making among pregnant women and prenatal care providers will need to be optimized, and the offering of prenatal screening will need to be measured. A whole-systems, centralized approach to screening - one that engages all components of a screening system in 
Table 2: Characteristics of the study cohort by trimester screened

\begin{tabular}{|c|c|c|c|c|c|}
\hline \multirow[b]{2}{*}{ Characteristic } & \multirow{2}{*}{$\begin{array}{l}\text { Total no. of } \\
\text { pregnancies }\end{array}$} & \multicolumn{3}{|c|}{ No. $(\%)$ of screened pregnancies* } & \multirow[b]{2}{*}{$p$ value } \\
\hline & & Total screened & First trimester & Second trimester & \\
\hline Total & 264737 & $164783(62.2)$ & $132355(50.0)$ & $32428(12.2)$ & \\
\hline \multicolumn{6}{|l|}{ Maternal age at delivery/abortion, yr } \\
\hline$\leq 20$ & 19622 & $7894(40.2)$ & $4986(25.4)$ & $2908(14.8)$ & $<0.001$ \\
\hline $21-34$ & 197976 & $122489(61.9)$ & $98308(49.7)$ & $24181(12.2)$ & \\
\hline$\geq 35$ & 47139 & $34400(73.0)$ & $29061(61.6)$ & $5339(11.3)$ & \\
\hline \multicolumn{6}{|l|}{ Maternal age at first delivery, yr } \\
\hline$\leq 20$ & 38411 & $16096(41.9)$ & $10786(28.1)$ & $5310(13.8)$ & $<0.001$ \\
\hline $21-34$ & 197873 & $126701(64.0)$ & $102750(51.9)$ & $23951(12.1)$ & \\
\hline$\geq 35$ & 28453 & $21986(77.3)$ & $18819(66.1)$ & $3167(11.1)$ & \\
\hline \multicolumn{6}{|l|}{ Parity (previous deliveries) } \\
\hline 0 & 134061 & $86098(64.2)$ & $69353(51.7)$ & $16745(12.5)$ & $<0.001$ \\
\hline 1 & 87628 & $56134(64.1)$ & $45820(52.3)$ & $10314(11.8)$ & \\
\hline 2 & 30525 & $17215(56.4)$ & $13396(43.9)$ & $3819(12.5)$ & \\
\hline$\geq 3$ & 12523 & $5336(42.6)$ & $3786(30.2)$ & $1550(12.4)$ & \\
\hline Previous delivery of stillborn child & 2163 & $1436(66.4)$ & $1160(53.6)$ & $276(12.8)$ & 0.7 \\
\hline Previous abortion in past $5 \mathrm{yr}$ & 39047 & $24504(62.8)$ & $19726(50.5)$ & $4778(12.2)$ & 0.4 \\
\hline $\begin{array}{l}\text { Previous delivery of child with } \\
\text { congenital anomaly }\end{array}$ & 9229 & $5284(57.3)$ & $4124(44.7)$ & $1160(12.6)$ & $<0.001$ \\
\hline \multicolumn{6}{|l|}{ Immigration status } \\
\hline Canadian resident & 193187 & $111734(57.8)$ & $92244(47.7)$ & $19490(10.1)$ & $<0.001$ \\
\hline \multicolumn{6}{|l|}{ Immigrant } \\
\hline Landed $\geq 5$ yr ago & 31308 & $23994(76.6)$ & $18691(59.7)$ & $5303(16.9)$ & \\
\hline Landed < 5 yr ago & 31274 & $22977(73.5)$ & $17082(54.6)$ & $5895(18.8)$ & \\
\hline \multicolumn{6}{|l|}{ Refugee } \\
\hline Landed $\geq 5$ yr ago & 5423 & $3679(67.8)$ & $2758(50.9)$ & $921(17.0)$ & \\
\hline Landed $<5$ yr ago & 3545 & $2399(67.7)$ & $1580(44.6)$ & $819(23.1)$ & \\
\hline \multicolumn{6}{|l|}{ Neighbourhood income quintile } \\
\hline 1 (lowest) & 60660 & $35653(58.8)$ & $25629(42.3)$ & $10024(16.5)$ & $<0.001$ \\
\hline 2 & 53750 & $32980(61.4)$ & 25485 (47.4) & $7495(13.9)$ & \\
\hline 3 & 53273 & 33367 (62.6) & $27270(51.2)$ & $6097(11.4)$ & \\
\hline 4 & 53604 & $34722(64.8)$ & $29687(55.4)$ & $5035 \quad(9.4)$ & \\
\hline 5 (highest) & 41928 & $27474(65.5)$ & $23912(57.0)$ & 3562 (8.5) & \\
\hline Missing data & 1522 & $587(38.6)$ & $372(24.4)$ & $215(14.1)$ & \\
\hline \multicolumn{6}{|l|}{ Rurality index score $\neq$} \\
\hline 0-9 (major urban) & 199919 & 136297 (68.2) & $111869(56.0)$ & $24428(12.2)$ & $<0.001$ \\
\hline 10-39 (non-major urban) & 45320 & $21222(46.8)$ & $15921(35.1)$ & 5301 (11.7) & \\
\hline$\geq 40$ (rural) & 16697 & $6457(38.7)$ & $4158(24.9)$ & $2299(13.8)$ & \\
\hline Missing data & 2801 & $807(28.8)$ & $407(14.5)$ & $400(14.3)$ & \\
\hline \multicolumn{6}{|l|}{ First-trimester care provider } \\
\hline Prenatal obstetrician & 84553 & $64726(76.6)$ & $55790(66.0)$ & $8936(10.6)$ & $<0.001$ \\
\hline Prenatal GP/FP & 118520 & $76385(64.5)$ & $63251(53.4)$ & $13134(11.1)$ & \\
\hline Primary GP/FP & 36684 & $18415(50.2)$ & $10460(28.5)$ & $7955(21.7)$ & \\
\hline Other physician & 7707 & 2997 (38.9) & 2063 (26.8) & $934(12.1)$ & \\
\hline Midwife only & 2562 & $684(26.7)$ & $572(22.3)$ & $112(4.4)$ & \\
\hline No care & 14711 & $1576(10.7)$ & $219 \quad(1.5)$ & $1357 \quad(9.2)$ & \\
\hline
\end{tabular}




\section{OPEN}

Research

a comprehensive and evaluative process ${ }^{45}$ — may be well suited to optimizing access and overall quality of this service. Specific attention will be needed to ensure access for women residing in remote areas and those who receive early prenatal care from nonobstetricians. Although our findings are specific to Ontario, pan-Canadian research and policy efforts are needed because of inconsistent funding and availability of prenatal screening in other jurisdictions. Increasing market-driven pressure from US-based vendors offering noninvasive prenatal testing that is not publicly funded ${ }^{46}$ will only add to access challenges. A unified and forward-thinking response from the prenatal care community is warranted.

\section{Table 3: Factors associated with prenatal screening}

\begin{tabular}{|c|c|c|c|}
\hline \multirow[b]{2}{*}{ Characteristic } & \multirow{2}{*}{$\begin{array}{c}\text { No. of pregnancies } \\
\quad n=264737\end{array}$} & \multicolumn{2}{|c|}{ Rate ratio $(95 \% \mathrm{Cl})$} \\
\hline & & Unadjusted & Adjusted $^{*}$ \\
\hline \multicolumn{4}{|l|}{ Maternal age at delivery/abortion, yr } \\
\hline$\leq 20$ & 19622 & $0.55(0.54-0.56)$ & $0.81(0.80-0.83)$ \\
\hline $21-34$ & 197976 & $0.85(0.84-0.86)$ & $0.94(0.93-0.95)$ \\
\hline$\geq 35$ & 47139 & 1.00 (ref) & 1.00 (ref) \\
\hline \multicolumn{4}{|l|}{ Maternal age at first delivery, yr } \\
\hline$\leq 20$ & 38411 & $0.54(0.53-0.55)$ & $0.85(0.84-0.86)$ \\
\hline $21-34$ & 197873 & $0.83(0.82-0.84)$ & $1.00(0.99-1.01)$ \\
\hline$\geq 35$ & 28453 & 1.00 (ref) & 1.00 (ref) \\
\hline \multicolumn{4}{|l|}{ Parity (previous deliveries) } \\
\hline 0 & 134061 & 1.00 (ref) & 1.00 (ref) \\
\hline 1 & 87628 & $1.00(0.99-1.01)$ & $0.97(0.96-0.97)$ \\
\hline 2 & 30525 & $0.88(0.87-0.89)$ & $0.89(0.89-0.90)$ \\
\hline$\geq 3$ & 12523 & $0.66(0.65-0.68)$ & $0.76(0.75-0.78)$ \\
\hline Previous delivery of stillborn child & 2163 & $1.07(1.04-1.10)$ & $1.04(1.03-1.06)$ \\
\hline Previous abortion in past $5 \mathrm{yr}$ & 39047 & $1.01(1.00-1.02)$ & $1.00(0.99-1.01)$ \\
\hline $\begin{array}{l}\text { Previous delivery of child with congenital } \\
\text { anomaly }\end{array}$ & 9229 & $0.92(0.90-0.93)$ & $1.00(0.99-1.02)$ \\
\hline \multicolumn{4}{|l|}{ Immigration status } \\
\hline Canadian resident & 193187 & 1.00 (ref) & 1.00 (ref) \\
\hline \multicolumn{4}{|l|}{ Immigrant } \\
\hline Landed $\geq 5$ yr ago & 31308 & $1.33(1.32-1.34)$ & $1.15(1.15-1.16)$ \\
\hline Landed $<5$ yr ago & 31274 & $1.27(1.26-1.28)$ & $1.15(1.14-1.16)$ \\
\hline \multicolumn{4}{|l|}{ Refugee } \\
\hline Landed $\geq 5$ yr ago & 5423 & $1.17(1.15-1.20)$ & $1.08(1.06-1.10)$ \\
\hline Landed $<5$ yr ago & 3545 & $1.17(1.14-1.20)$ & $1.10(1.08-1.12)$ \\
\hline \multicolumn{4}{|l|}{ Neighbourhood income quintile } \\
\hline 1 (lowest) & 60660 & $0.90(0.89-0.91)$ & $0.95(0.94-0.96)$ \\
\hline 2 & 53750 & $0.94(0.93-0.95)$ & $0.97(0.96-0.98)$ \\
\hline 3 & 53273 & $0.96(0.95-0.97)$ & $0.97(0.96-0.98)$ \\
\hline 4 & 53604 & $0.99(0.98-1.00)$ & $0.98(0.98-0.99)$ \\
\hline 5 (highest) & 41928 & 1.00 (ref) & 1.00 (ref) \\
\hline Missing data & 1522 & $0.59(0.55-0.63)$ & $0.97(0.93-1.01)$ \\
\hline \multicolumn{4}{|l|}{ Rurality index score $†$} \\
\hline 0-9 (major urban) & 199919 & 1.00 (ref) & 1.00 (ref) \\
\hline 10-39 (non-major urban) & 45320 & $0.69(0.68-0.70)$ & $0.76(0.75-0.76)$ \\
\hline$\geq 40$ (rural) & 16697 & $0.57(0.56-0.58)$ & $0.67(0.66-0.68)$ \\
\hline Missing data & 2801 & $0.42(0.40-0.45)$ & $0.63(0.60-0.67)$ \\
\hline \multicolumn{4}{|l|}{ First-trimester health care provider } \\
\hline Prenatal obstetrician & 84553 & 1.00 (ref) & 1.00 (ref) \\
\hline Prenatal GP/FP & 118520 & $0.84(0.83-0.85)$ & $0.91(0.90-0.92)$ \\
\hline Primary GP/FP & 36684 & $0.66(0.65-0.66)$ & $0.72(0.71-0.73)$ \\
\hline Other physician & 7707 & $0.51(0.49-0.52)$ & $0.65(0.64-0.67)$ \\
\hline Midwife only & 2562 & $0.35(0.33-0.37)$ & $0.40(0.38-0.43)$ \\
\hline No care & 14711 & $0.14(0.13-0.15)$ & $0.15(0.14-0.16)$ \\
\hline
\end{tabular}




\section{References}

1. Chitayat D, Langlois S, Wilson RD, et al. Prenatal screening for fetal aneuploidy in singleton pregnancies: CCMG-SOGC clinical practice guideline. 7 Obstet Gynaecol Can 2011;33:736-50.

2. Benn P, Borell A, Chiu R, et al. Position statement from the Aneuploidy Screening Committee on behalf of the Board of the International Society for Prenatal Diagnosis. Prenat Diagn 2013;33:622-9.

3. Wilson JM, Jungner YG. Principles and practice of mass screening for disease. Bol Oficina Sanit Panam 1968;65:281-393.

4. Raffle A, Gray M. Screening: evidence and practice. New York: Oxford University Press; 2009.

5. Tapon D. Prenatal testing for Down syndrome: comparison of screening practices in the UK and USA. 7 Genet Couns 2010;19:112-30.

6. Boyd PA, Devigan C, Khoshnood B, et al. Survey of prenatal screening policies in Europe for structural malformations and chromosome anomalies, and their impact on detection and termination rates for neural tube defects and Down's syndrome. BfOG 2008; 115:689-96.

7. Okun N, Summers AM, Hoffman B, et al. Prospective experience with integrated prenatal screening and first trimester combined screening for trisomy 21 in a large Canadian urban center. Prenat Diagn 2008;28:987-92.

8. Summers AM, Farrell SA, Huang T, et al. Maternal serum screening in Ontario using the triple marker test. 7 Med Screen 2003;10:107-11.

9. Lalania $\mathrm{S}$, Laua $\mathrm{W}$. Non-invasive prenatal diagnosis - a new era. UBC Med 7 2013;4:29-31.

10. Rose NC, Lagrave D, Hafen B, et al. The impact of utilization of early aneuploidy screening on amniocenteses available for training in obstetrics and fetal medicine. Prenat Diagn 2013;33:242-4

11. Morgan S, Delbarre A, Ward P. Impact of introducing a national policy for prenatal Down syndrome screening on the diagnostic invasive procedure rate in England. Ultrasound Obstet Gynecol 2013;41:526-9.

12. Non-invasive prenatal testing (NIPT) for Down's syndrome. London (UK): Antenatal Results and Choices. Available: www.arc-uk.org/tests-explained/non -invasive-prenatal-testing-nipt (accessed 2015 June 4).

13. Morris S, Karlsen S, Chung N, et al. Model-based analysis of costs and outcomes of non-invasive prenatal testing for Down's syndrome using cell free fetal DNA in the UK National Health Service. PLoS ONE 2014;9:e93559.

14. Agarwal A, Sayres LC, Cho MK, et al. Commercial landscape of non-invasive prenatal testing in the United States. Prenat Diagn 2013;33:521-31.

15. Carroll JC, Brown JB, Reid AJ, et al. Women's experience of maternal serum screening. Can Fam Physician 2000;46:614-20.

16. Gidiri M, McFarlane J, Holding S, et al. Maternal serum screening for Down syndrome: Are women's perceptions changing? B7OG 2007;114:458-61.

17. Dormandy E, Michie S, Hooper R, et al. Low uptake of prenatal screening for Down syndrome in minority ethnic groups and socially deprived groups: A reflection of women's attitudes or a failure to facilitate informed choices? Int 7 Epidemiol 2005;34:346-52

18. Williams C, Sandhall J, Lewando-Hundt G, et al. Women as moral pioneers? Experiences of first trimester antenatal screening. Soc Sci Med 2005;61:1983-92 .

19. van den Berg M, Timmermans DRM, Kleinveld DH, et al. Are counselors' attitudes influencing pregnant women's attitudes and decisions on prenatal screening? Prenat Diagn 2007;27:518-24.

20. Spencer K, Aitken D. Factors affecting women's preference for type of prenatal screening test for chromosomal anomalies. Ultrasound Obstet Gynecol 2004;24:735-9.

21. Permaul-Woods JA, Carroll JC, Reid AJ, et al. Going the distance: the influence of practice location on the Ontario Maternal Serum Screening Program. CMA7 1999;161:381-5.

22. Carroll JC, Reid AJ, Woodward CA, et al. Ontario Maternal Serum Screening Program: practices, knowledge and opinions of health care providers. CMA7 1997; 156:775-84

23. Dormandy E, Marteau TM. Uptake of a prenatal screening test: the role of health care professionals' attitudes towards the test. Prenat Diagn 2004:24:864-8.

24. Cavanagh J, Matthews M. Maternal serum screening in Newfoundland and Labrador: Do attitude and knowledge affect physicians' practice? Can Fam Physician 2006;52:1268-9.

25. Chandra S, Crane J, Hutchens D, et al. Maternal serum screening: practice patterns of physicians in Newfoundland. 7 Obstet Gynaecol Can 2003;25:825-9.

26. Khoshnood B, Blondel B, De VC, et al. Socioeconomic barriers to informed decision making regarding maternal serum screening for down syndrome: results of the French National Perinatal Survey of 1998. Am 7 Public Health 2004;94:484-91.

27. Khoshnood B, De Vigan C, Blondel B, et al. Long term trends for socio-economic differences in prenatal diagnosis of Down syndrome: Diffusion of services or persistence of disparities? B7OG 2008;115:1087-95.

28. Maxwell S, Brameld K, Bower C, et al. Socio-demographic disparities in the uptake of prenatal screening and diagnosis in western Australia. Aust NZ 7 Obstet Gynaecol 2011;51:9-16.

29. Rowe RE, Garcia J, Davidson LL. Social and ethnic inequalities in the offer and uptake of prenatal screening and diagnosis in the UK: a systematic review. Public Health 2004;118:177-89.

30. Rowe R, Puddicombe D, Hockley C, et al. Offer and uptake of prenatal screening for Down syndrome in women from different social and ethnic backgrounds. Prenat Diagn 2008;28:1245-50.

31. Muggli EE, Collins VR, Halliday JL. Mapping uptake of prenatal diagnosis for
Down syndrome and other chromosome abnormalities across Victoria, Australia. Aust N Z7 Obstet Grnaecol 2006:46:492-500.

32. O'Leary P, Breheny N, Reid G, et al. Regional variations in prenatal screening across Australia: stepping towards a national policy framework. Aust $N Z \mathcal{F}$ Obstet Gynaecol 2006;46:427-32

33. Ontario Prenatal Screening Advisory Subcommittee. Prenatal screening in Ontario: the road forward. Policy report submitted to the Ontario MaternalChild Screening Committee, June 2013.

34. Chan B. Supply of physicians services in Ontario. Hosp Q 1999-2000;3:17.

35. Iron K, Zagorski BM, Sykora K, et al. Living and dying in Ontario: an opportunity for improved health information. ICES Investigative Report. Toronto: Institute for Clinical Evaluative Sciences; 2008.

36. Jutte DP, Roos NP, Brownell MD, et al. The ripples of adolescent motherhood social, educational, and medical outcomes for children of teen and prior teen mothers. Acad Pediatr 2010;10:293-301.

37. Dunn S, Wise MR, Johnson LM, et al. Reproductive and gynaecological health. In: Bierman AS, editor. Project for an Ontario women's bealth evidence-based report. Vol. 2. Toronto: St. Michael's Hospital/ICES; 2012.

38. Campitelli MA, Inoue M, Calzavara AJ, et al. Low rates of influenza immunization in young children under Ontario's universal influenza immunization program. Pediatrics 2012;129:e1421-30.

39. Wilkins R, Khan S. PCCF + version 5 H user's guide. Automated geographic coding based on the Statistics Canada Postal Code Conversion files, including postal codes through October 2010. Ottawa: Statistics Canada; 2010. Cat. no. 82F0086-XDB.

40. Finkelstein MM. Ecologic proxies for household income: How well do they work for the analysis of health and health care utilization? Can 7 Public Health 2004;95:90-4.

41. Kralj B. Measuring "rurality" for purposes of health care planning: an empirical mea sure for Ontario. Toronto: Ontario Medical Association; 2005.

42. McNutt LA, Wu C, Xue X, et al. Estimating the relative risk in cohort studies and clinical trials of common outcomes. Am 7 Epidemiol 2003;157:940-3.

43. Lofters AK, Moineddin R, Hwana SW, et al. Low rates of cervical cancer screening among urban immigrants: a population-based study in Ontario, Canada. Med Care 2010;48:611-8

44. Gagnon A, Wilson RD, Audibert F, et al.; Society of Obstetricians and Gynaecologists of Canada Genetics Committee. Technical update: obstetrical complications associated with abnormal maternal serum marker analytes. 7 Obstet Gynecol 2008;10:918-49.

45. Hayeems RZ, Chakraborty P. A practical definition and key concepts of population-based screening. BORN Bulletin 2012;3

46. Morain S, Greene MF, Mello MM. A new era in non-invasive prenatal testing. NEngl 7 Med 2013;369:499-501.

Affiliations: Child Health Evaluative Sciences (Hayeems), Hospital for Sick Children Research Institute, Toronto, Ont.; Institute of Health Policy, Management and Evaluation (Hayeems, Guttmann), University of Toronto, Toronto, Ont.; Institute for Clinical Evaluative Sciences (Campitelli, Ma, Guttmann), Toronto, Ont.; Genetics Program (Huang), North York General Hospital, Toronto, Ont.; Better Outcomes Registry and Network (BORN) Ontario (Huang, Walker), Ottawa, Ont.; Ottawa Hospital Research Institute (Walker), Ottawa, Ont.; Division of Maternal-Fetal Medicine, Department of Obstetrics and Gynecology (Walker), University of Ottawa, Ottawa, Ont.; Hospital for Sick Children and Department of Paediatrics (Guttmann), University of Toronto, Toronto, Ont.

Contributors: All of the authors contributed substantially to the conception and design of the study, and the acquisition, analysis and interpretation of data. Robin Hayeems, Michael Campitelli and Astrid Guttmann drafted the article, and all of the authors revised it critically for important intellectual content. All of the authors approved the final version to be published and agreed to be guarantors of the work.

Funding: The study was funded by the Ontario Ministry of Health and Long-Term Care (MOHLTC) and was made possible by the Institute for Clinical Evaluative Sciences (ICES). ICES is a nonprofit organization funded by the MOHLTC. No endorsement by ICES or the MOHLTC is intended or should be inferred. The funding bodies had no role in the design or conduct of the study; the collection, analysis or interpretation of the data; or the preparation, review or approval of the manuscript.

Acknowledgements: The authors thank Kelvin Lam for assisting with the creation of the regional map depicted in Figure 1.

Astrid Guttmann receives salary support from an Applied Chair in Child and Youth Health Services Research from the Canadian Institutes of Health Research, and Mark Walker receives salary support from a Tier 1 Research Chair in Perinatal Research at the University of Ottawa.

Supplemental information: For reviewer comments and the original submission of this manuscript, please see www.cmajopen.ca/content/3/2/E236/ suppl/DC1 